The Canadian Journal of Higher Education

\title{
The Effects of a Peer Mentoring Program on Academic Success Among First Year University Students
}

\section{SUSAN RODGER \& PAUL F. TREMBLAY}

The University of Western Ontario

\section{ABSTRACT}

The present study examines the effect of participation of first-year university students in a full-year peer mentoring program as well as individual differences in motivation in relation to outcome measures of retention and achievement. A sample of 983 first year students completed the Academic Motivation Inventory (Tremblay, 1998) and agreed to provide final grades; 537 students were randomly assigned to participate in the program, while the remainder served as a control group. Mentored students who continued to participate mid-way through the second semester had significantly higher final grades than did students in the control group. There was no effect on retention from year one to year two, however data are being collected on retention and grades for all groups for the length of their undergraduate careers. Students high in anxiety in the mentored group showed achievement comparable to that of low anxiety program participants, whereas students in the control group with high anxiety scored significantly worse on achievement than did their low anxiety counterparts. 


\section{RÉSUMÉ}

La présente étude a examiné les répercussions de la participation d'étudiants de première année impliqués, pendant un an, dans un programme de mentorat de pairs, ainsi que les différents niveaux de motivation en rapport avec les résultats mesurés de rétention et de réussite. Un échantillon de 983 étudiants de première année ont complété l'inventaire de motivation académique (Tremblay, 1998) et ont accepté de soumettre leurs notes finales; 537 étudiants ont été choisis au hasard pour participer au programme, tandis que le groupe restant allait faire fonction de groupe contrôle. Les étudiants bénéficiant de l'appui du programme de mentorat qui sont restés jusqu'à la moitié du second semestre ont obtenu des notes considérablement plus élevées que ceux dans le groupe contrôle. Auçun effet sur la rétention n'a été observé entre la première et la deuxième année, mais toutefois des données continuent d'être recueillies dans ce domaine, ainsi que dans celui des notes obtenues par tous les groupes au cours des quatre premières années de scolarisation universitaire. Les étudiants plus angoissés impliqués dans le groupe de mentorat ont aussi bien réussi que les participants du même groupe qui l'étaient moins, tandis que les étudiants du groupe contrôle souffrant d'un niveau d'anxiété élevé ont considérablement moins bien réussi que leurs homologues qui y étaient moins sujets.

One type of intervention that is becoming increasingly popular in higher education is mentoring of first-year students by faculty and senior students. This formal mentoring process is widely believed to be related to positive outcomes for both the mentor and mentee (Ragins \& Cotton, 1999, Seibert, 1999). Reasons for mentoring include institutional goals such as recruitment and retention of students (Jacobi, 1991), pedagogical goals such as increasing learning, and enhancing relationships with faculty and other students (Upcraft, 1989). The present study employs a rigorous experimental design to test the effect of mentoring on academic achievement and retention among first year university students.

In the competition for recruitment and retention of students, colleges and universities offer a myriad of programs, support services, and 
resources. Attempts to evaluate the impact of these programs, particularly in the area of student retention, are characterized by poor methodological quality, making conclusions about their effectiveness difficult. In fact, a meta-analysis of 500 retention program research studies in college reported that only 60 , or $12 \%$, were of acceptable methodological quality (Kulik, Kulik and Shwalb, 1983).

Similar observations have been made with respect to the research on the effects of mentoring in college. Jacobi (1991) reviewed the literature on mentoring and undergraduate academic success and concluded that the popular opinion was that mentoring is a critical component of effective undergraduate education. Furthermore, although descriptions of mentoring programs designed to promote academic success are common in the higher education literature, substantially fewer systematic evaluations are available, and those reports that do provide evaluation often have methodological problems. Jacobi goes on to conclude that, "The concept of mentoring remains unclear and imprecise, and the effectiveness of informal or formal mentoring in promoting undergraduate academic success is assumed rather than demonstrated." (p. 526). Jacobi (1991) highlights a number of specific methodological weakness in the studies included in her review, including non-random selection or assignment to conditions, lack of cross-sectional research, little or no measurement of individual differences, use of single outcome measures administered just once, and lack of generalizability. The present study addresses each one of these shortcomings by using a large sample of students, random assignment of students to groups, participants from eight faculties, and comprehensive measures of academic motivation.

The methodological weaknesses of previous studies are compounded by an overarching problem, the lack of a theoretical explanation for why such programs might be effective. The three most promising theoretical explanations for the potential positive effects of mentoring can be derived from social, cognitive, and motivation perspectives. The social perspective suggests that peers can influence both persistence (that is, staying in school as compared to dropping out) and feelings of belongingness (Bank, Slavings \& Biddle, 1990), the acquisition and development of satisfying relationships with members of the organization 
(Allen, McManus \& Russell, 1999) and satisfaction (Seibert, 1999). The cognitive perspective emphasizes the effects of peer interaction such as reciprocal peer tutoring on the development of cognitive skills such as self-questioning (Fantuzzo, Riggio, Connelly \& Dimeff, 1989) and study habits (Berndt, 1999), and would account for the negative influence of student characteristics such as lack of study skills and high levels of anxiety on cognitive processing (Hembree, 1988). Finally, a motivation explanation proposes that peer mentoring influences self-efficacy and help-seeking behaviour (Hayes, 1999; Karabenick \& Knapp, 1999).

Two hypotheses were derived for the present study based on a review of the literature on the sources of influence on educational outcomes for first year students. First, it is expected that peer mentoring would positively affect students' academic achievement. Second, it is predicted that peer mentoring would increase the retention of mentored students between freshman and sophomore years.

\section{METHOD}

\section{Participants}

A total of 983 of 4400 incoming first-year university students at The University of Western Ontario submitted applications to be mentored by an upper-year student (Peer Mentor). From this sample of applicants, or volunteers, 537 students were randomly selected to participate in the program (Peer Mentored Group). They were selected proportionally across seven faculties (Arts, Social Science, Science, Engineering Science, Health Science, Music, and Information and Media Studies) and across four levels of self-reported academic motivation (Low, Moderately Low, Moderately High and High), based on scores from the Academic Motivation Inventory (Tremblay, 1998). The remaining 446 applicants (Applicant Control Group), formed a true, randomly assigned control group, also selected proportionally across four levels of motivation. A third group consisting of 506 students selected at random from the total population of first year students not applying to the program was also included as a second control group (Non-Applicant Control Group). 


\section{Measures}

Demographic measures. Students self-reported the following demographic variables: age, sex, population of hometown, parents' yearly income, number of courses taken in the last year of secondary school, most advanced mathematics course completed, and grade in that course. This particular grade was selected as a variable of interest because of the perceived relationship between senior mathematics grades and subsequent academic achievement in science and social science programs, the programs that accounted for the largest number of first year students at the institution.

Motivation measures. Students were asked to estimate the number of hours they planned to study each week in university. This question was asked for two main reasons. First, good study habits (of which the number of hours a student plans to study is one) has been linked to academic achievement (Lin \& McKeachie, 1970). Second, the results of this question were used later, for the purposes of educating new students regarding what they should expect in terms of the number of hours they should study in order to have the best chance at academic success.

Students also completed the Academic Motivation Inventory (Tremblay, 1998). This measure consists of 128 five-point Likert scale items divided among 12 scales, four of which are valence or incentive dimensions (Stimulation, Mastery, Recognition, and Acquisition). The other scales are Goal Salience, Self-Efficacy, Effort, Attention, Persistence, Facilitating Anxiety, Debilitating Anxiety, and Socially Desirable Responding. A general motivation score was computed by summing the following related scales: Stimulation, Mastery, Goal Salience, Effort, Attention, and Persistence. For the purpose of this study, the general motivation score and the Debilitating Anxiety scale were used. This anxiety scale has an alpha value of .85 and assesses the debilitating experience of anxiety in a variety of academic situations such as exams and presentations. The general motivation measure has a Cronbach alpha value of .94 .

Achievement measures. These consisted of the overall secondary school grades in final year and final grades in first-year university, both on a 100-point percentage scale as provided by the students (in the case 
of high school grades) and the university (in the case of final grades at the end of the first year of study). Students who received grades lower than 45 were assigned a grade of 45 for this study to eliminate the spurious effect of outliers.

Level of participation. This measure applies to the Peer Mentor group only and was provided by the peer mentors halfway into the second semester. The peer mentors were asked to assign a numerical rating of 0 to 5 to each student in their group reflecting level of participation in Peer Mentor-First Year Student activities and events. Surveys were then collected and results tabulated. The rating system, with higher numbers indicating higher levels of participation and each level subsuming the previous one, was defined in the following manner: A " 0 " indicated that students had not contacted their peer mentors at all; 1 indicated that the first year student attended only the first large-group event (the program kick-off); " 2 " was defined as attending only the 3 large-group events (the kick-off event plus a large pizza-and-study gathering held in November and late January); a rating of " 3 " indicated that the first year student attended at least 3 other regularly scheduled small-group meetings; a rating of " 4 " indicated that students were meeting their peer mentor at least once per month; a rating of " 5 " indicated that first year students met with their peer mentors at least once every two weeks for the academic year.

Retention. The number of students from each of the three groups who returned and those who did not return for their second year of university studies were counted. It should be noted that for the Non Applicant Control Group, only retention data and grades were obtained; in other words, this group did not complete the Academic Motivation Inventory or the demographic survey.

\section{Design and Procedure}

Applicants for the peer mentorship program completed a questionnaire providing demographic and biographic data (as described above). All applicants signed an informed consent form granting permission to the researchers to examine past and future grades and retention data. Applicants attended an information session prior to the beginning of the 
academic year and were asked to complete the Academic Motivation Inventory on a voluntary basis, with the understanding that refusal to complete the inventory would in no way affect their chances of being selected for peer mentorship. Applicants were told that they were not guaranteed entry into the program, but rather that there would be a random selection taking place across faculty.

\section{Selection and training of peer mentors.}

The Position Analysis Questionnaire (McCormick, Jeanneret \& Mecham, 1989) was used to analyze the positions of Peer Mentor and Mentor Team Leaders, and this information was used to write the job descriptions as well as to guide the selection and training processes. Peer Mentors were selected from a pool of applicants and received both initial and on-going training. Support was provided by Mentor Team Leaders and a Program Coordinator. Each Peer Mentor was assigned a group of five to seven students. The 95 Peer Mentors were in the same faculty, and in most cases the same program, as their students and shared long-term academic and/or career goals such as graduate study or professional careers. Small groups of Peer Mentors were also matched with one of 21 Mentor Team Leaders, consisting of 4 th year students who were members of the same faculty. Furthermore, a total of 22 Faculty Mentors (professors) volunteered to meet with the groups and their Mentor Team Leaders periodically.

\section{Interaction between peer mentors and students}

In late August, applicants received letters advising them whether they had been selected for the Peer Mentorship group. Students who applied but were not selected were given a list of services and resources to aid in academic transition, such as a learning skills centre. Students who were selected were sent an invitation to a Kick-Off event, scheduled three weeks after the beginning of classes, and were assigned to a Peer Mentor. Peer Mentors initiated and maintained weekly contact with their groups, either in person or via e-mail or telephone. Peer Mentors were instructed not to tutor their first year students, but were instead encouraged to share their own experiences of being a first year student in their 
faculty, and to help first year students prepare for the academic challenges. This message was reinforced during the training phases and weekly meetings for Peer Mentors. Team Leaders attended, on a rotating basis, meetings of each Peer Mentor's group with the goal of introducing themselves and their expertise/experience to the first-year students and checking to make sure that tutoring was not being provided by the Peer Mentors. The withholding of any tutoring was considered to be important for two main reasons. First, it was determined early on that one of the goals of the program was to help students get to know the resources at the university and develop the study skills necessary for academic success, and tutoring by the Peer Mentor would interfere with attainment of these goals. Second, first year students may have expected that, because they were meeting and receiving tutoring regularly, there might be a positive impact on their grades, and this expectation might negatively influence their academic success.

\section{Program Features}

Peer Mentors met weekly with other Mentors and a Team Leader for their particular faculty. These meetings were standard across faculties such that weekly topics followed the flow of the academic year, such as providing study tips about 2 weeks before the first set of exams. Following this weekly Team Meeting, Peer Mentors would meet with their first year students and pass on what they had learned, so that all attendees were getting basically the same information and resources at around the same time, across the campus.

Regular activities varied among Peer Mentors, but ranged from regular weekly meetings featuring study tips and introductions to campus resources such as library services, to off-campus trips to visit professionals in their field such as dentists and lawyers (for groups with these professions as a shared goal) to engaging in volunteer work together. Students who had a Peer Mentor were encouraged (through modeling and support from their peer mentor) to take advantage of the many academic resources available on campus such as learning skills workshops and library orientation sessions, and to get involved in the campus community (first term) and the off-campus community (second term). 
Regular activities also included question and answer sessions with faculty members to inquire about areas of expertise, research interests, and possibilities for student participation in research projects.

\section{RESULTS}

\section{Effects of Peer Mentoring on Academic Performance}

A one-way analysis of variance comparing the peer mentoring treatment to the two control groups in terms of average final grade in first year university courses revealed no significant differences, $\underline{F}(2,1410)=1.31$. Mean scores for the three groups were as follows: Peer Mentored Group $(\underline{M}=69.71, \underline{\mathrm{SD}}=9.67)$, Applicant Control Group $(\underline{\mathrm{M}}=69.32, \underline{\mathrm{SD}}=11.05)$, and Non-applicant Control Group $(\underline{\mathrm{M}}=68.65, \underline{\mathrm{SD}}=10.68)$.

In order to control for potential confounding effects of motivation and previous grades, differences were inspected in these variables between the Peer Mentored Group and the Applicant Control Group. The motivation measure, as noted above, was the sum of six scales of the Academic Motivation Inventory. Data on these variables were not available for the Non-applicant control group. Table 1 presents the descriptive statistics for the two groups. No significant differences were found between the two groups in motivation, $\underline{t}(1,817)=1.25$, or in previous grades $t(1,817)=1.03(\mathrm{~N}=983)$. It should be noted that nonsignificant differences in motivation and prior grades were anticipated at the onset of the study, because participants were randomly assigned to groups, with equal representation across four motivation levels. Thus the

Table 1

Motivation and Previous Grade Means and Standard Deviations for the Peer Mentored Group and the Applicant Control Group

\begin{tabular}{lcccc} 
Group & \multicolumn{2}{c}{ Motivation } & \multicolumn{2}{c}{ Previous Grades } \\
& $\underline{\mathrm{M}}$ & $\underline{\mathrm{SD}}$ & $\underline{\mathrm{M}}$ & $\underline{\mathrm{SD}}$ \\
Peer Mentored Group & 66.97 & 10.95 & 81.83 & 5.78 \\
Applicant Control Group & 67.77 & 11.03 & 82.35 & 5.96
\end{tabular}


nonsignificant group differences provide a check on the efficiency of random assignment. Furthermore a second analysis of variance was conducted of the same two groups, entering Motivation and Previous Grades as covariates. First year grade differences between the Peer Mentored Group $(\underline{M}=70.12)$ and the Applicant Control Group $(\underline{M}=69.21)$ were again non-significant, $\underline{\mathrm{F}}(1,815)=2.89$.

One potential reason for the lack of significant differences between groups is participation level in peer mentoring. That is, some students in the Peer Mentored Group did not attend all the peer mentored activities or meet with their peers on a regular basis. In order to investigate this hypothesis, the Peer Mentored Group was modified to include only students who had received scores of 4 or 5 out of 5 on the participation rating. Recall that a score of 4 indicated that students were meeting their peer mentor at least once per month and a rating of 5 indicated that they met with their peer mentors at least every two weeks. A total of 231 students obtained scores of 4 or 5 . (Of these, 222 provided their final grades.) This new group was labeled the Modified Peer Mentor Group. One potential confound in selecting individuals with high participation is motivation. For example, if one hypothesized that the selected individuals in the Modified Peer Mentored Group would have higher grades than individuals in the control groups, the differences may be due to academic motivation and not necessarily participation in peer mentoring activities. To test whether motivation was a potential confound we calculated the correlation between participation scores and motivation, and we found a nonsignificant correlation, $\underline{r}=.06$. Furthermore the mean motivation score for the Modified Peer Mentor Group was 67.74 and did not differ significantly from the mean motivation score of the Applicant Control Group $(\underline{\mathrm{M}}=67.77)$.

This suggested that motivation was not a confound, and an analysis of variance was conducted comparing the Modified Peer Mentored group to the two control groups. The analysis revealed significant differences among the groups $(\underline{F}(2,1126)=3.29, \underline{p}<.05)$. Tukey HSD tests of group means revealed that the Modified Peer Mentored Group $(\underline{M}=70.86$, $\underline{\mathrm{SD}}=9.86$ ) differed significantly from the Non-applicant Control Group 
$(\underline{M}=68.65, \underline{\mathrm{SD}}=10.68, \mathfrak{g}(3,1126)=3.63, \underline{\mathrm{p}}<.05)$, but not from the Applicant Control Group $(\underline{\mathrm{M}}=69.32, \underline{\mathrm{SD}}=11.05), \underline{\mathrm{q}}=2.44, \underline{\mathrm{p}}<.05)$.

\section{Interaction of Debilitating Anxiety and Peer Mentoring}

The impact of debilitating anxiety on academic performance was also investigated. A median-split debilitating anxiety score was computed. An analysis of variance was conducted with the Anxiety level Mentoring treatment (Peer Mentoring vs. Applicant Control) as the independent variables and academic performance (final grades) as the dependent variable. The analysis revealed a significant anxiety effect, $\underline{F}(1,828)=15.52, \mathfrak{p}<.01$. The low Anxiety group had a mean grade of $70.74(\underline{S D}=10.10)$ while the high Anxiety group had a mean of 68.21 $(\underline{S D}=10.15)$. A significant interaction between Anxiety and the Mentoring treatment was also found, $\underline{F}(1,828)=6.28, \underline{p}<.05$. Posthoc tests of means (Tukey, HSD) revealed no significant differences in grades among Low and High Anxiety students in the Peer Mentored group $(q=1.55$, n.s.), but significant differences in grades among Low

Figure 1

Grade as a function of peer mentoring and anxiety.

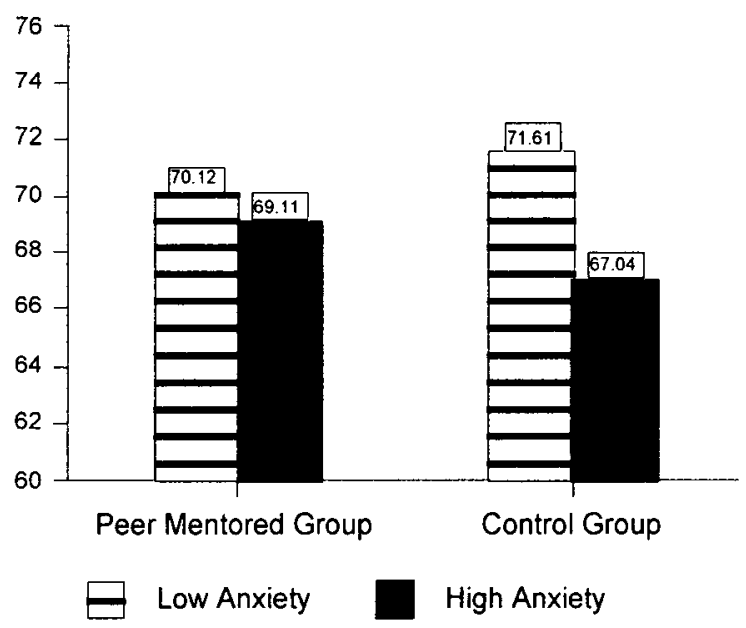


and High Anxiety students in the Control Group $(\mathrm{q}=6.01, \mathrm{p}<.01)$. Figure 1 illustrates the nature of the mean differences.

\section{The Effect of Peer Mentorship on Retention After First Year}

In order to determine whether Peer Mentorship has an effect on post Year 1 university retention rates, the study investigated the proportions of students across the three groups (Peer Mentored, Applicant Control, and Non Applicant Control) who returned to university in the second year. A Chi square test of independence revealed no significant differences among the three groups, $X^{2}(2)=2.08$, ns. Proportions of students in the Peer Mentored, Applicant Control, and Non Applicant Control who returned to university in the second year were $84.5 \%, 81.4 \%$, and $84.4 \%$ respectively.

The above analysis was repeated comparing the Modified Peer Mentored Group to the two control groups. Recall that the Modified Peer Mentored Group consists of those students who obtained mentorship participation scores of 4 or 5 . A Chi square test of independence revealed no significant differences among the three groups, $X^{2}(2)=2.83$, ns. Proportions of students in the Modified Peer Mentored, Applicant Control, and Non Applicant Control who returned to university in the second year were $86.1 \%, 81.4 \%$, and $84.4 \%$ respectively.

\section{DISCUSSION AND CONCLUSIONS}

The results of this study provided only partial support for the hypothesis that peer mentoring would have a positive effect on achievement. No support was found for this hypothesis when the Peer Mentored Group was compared to the two control groups. However, when participation level among Peer Mentored students was taken into account, a positive effect was detected. In terms of future research, then, looking more carefully at participation in this type of research is of paramount importance. There are clearly individual differences in level of participation in a peer mentoring program because students are free to attend or not to attend the organized activities. This study revealed that participation is not contingent on level of academic motivation, and given that 
students with high levels of participation (Modified Peer Mentor Group) experienced significantly higher grades, more research is needed to identify what influences participation.

The results comparing the Peer Mentored Group and the Applicant Control Group revealed an especially intriguing finding with respect to the interaction with a student individual difference - debilitating anxiety. The overall negative relationship between anxiety and academic achievement reported by Hembree (1988) was supported by the results in this study, but the interaction between peer mentoring, test anxiety and achievement may provide an explanation of the ways mentoring can influence student achievement. In the Peer Mentored Group, students high in anxiety experienced grades comparable to those of their low anxiety counterparts, while in the Applicant Control Group, students with high anxiety did significantly worse than low anxiety students. Explanations for this interaction could include the possibility of an alleviation of anxiety in that peer mentors were encouraged to share personal experiences regarding their early university studies and academic success, specifically examples that featured poor academic results and, later, improved results, suggesting that success may be attributable to (unstable) effort and persistence and not (stable) ability. Research supports this possible explanation in so far as the relation between high anxiety and locus of control. High anxiety is linked to an external locus of control (Hembree, 1988), and students with an external locus of control who receive attributional retraining (where students were exposed to a professor recounting stories about a bumpy undergraduate career, and reassured by the professor that he or she had survived and eventually triumphed over academic challenges) achieved grades significantly higher than that of their external locus of control counterparts who did not receive attribution retraining (Perry \& Penner, 1990).

An explanation for the cognitive influence of mentoring may be that the first year students received study tips or other cognitive skill training from their peer mentor. Research suggests that high anxiety students, compared to their low anxiety counterparts, have lower levels of study skills (Culler \& Holahan, 1980) and information processing skills (McKeachie, 1984). Further, there is evidence supporting the notion that 
both information processing and study skills can improve through treatments that include both cognitive-behavioural and study skills instruction (Hembree, 1988). Finally, the social influence explanation would hold if it was discovered that first year students in the peer mentoring program had a greater sense of belonging, or felt more comfortable with their peer group, and this resulted in lowering the levels of anxiety among high anxiety students so that this did not have a negative effect on achievement. Of course, this relationship could be explained by a combination of some or all of these factors, and none of the possible theoretical implications have been ruled out.

One important practical implication of the present study is in terms of the best use of resources. When academic departments or units are faced with limited resources and must make choices about which programs to fund, which students to help, and what outcomes may be influenced, it may be helpful to have information that provides direction and focus for decision-makers. The present research has promise in its ability to target students who would benefit most from a peer mentoring program, and so use existing resources wisely. In the case where the numbers of participants are not limited by resources, it may be important to know, as was found in this case, that peer mentoring worked particularly well for some students (i.e. those high in anxiety).

The final point here is that the results of peer mentoring on retention and academic achievement have only been evaluated in the short-term. These students will be assessed throughout their entire university education, to evaluate the longer term influence of mentoring, as effects may not emerge until the 2 nd, 3 rd, or even 4 th year of study.

These evaluations are just part of the further research that needs to be carried out in order to make firm conclusions about mentoring programs at university. Jacobi (1991) concluded her call for further research in this area by providing a long list of questions that have yet to be answered about mentoring and academic outcomes, and reminds us that until such research is done, the concept of mentoring remains unclear and imprecise and the effectiveness of mentoring in promoting undergraduate academic success is assumed rather than demonstrated. 


\section{References}

Allen, T.D., McManus, S.E. \& Russell, J.E. (1999). Newcomer socialization and stress: Formal peer relationships as a source of support. Journal of Vocational Behaviour, 54, 453-470.

Bank, B.J., Slavings, R.L., \& Biddle, B. (1990). Effects of peer, faculty, and parental influence on students' persistence. Sociology of Education, 63 (July), 208-225.

Berndt, T.J. (1999). Friends' influence on students' adjustment to school. Educational Psychologist, 34(1), 15-28.

Culler, R.E. \& Holahan, C.J. (1980). Test anxiety and academic performance: The effects of study-related behaviors. Journal of Educational Psychology, 72(1), 16-20.

Fantuzzo, J.W., Riggio, R.E., Connelly, S., \& Dimeff, L.A. (1989). Effects of reciprocal peer tutoring on academic achievement and psychological adjustment: A component analysis. Journal of Educational Psychology, 81(2), 173-177.

Hayes, E. F. (19998). Mentoring and nurse practitioner student selfefficacy. Western Journal of Nursing Research, 20(5), 521-535.

Hembree, R. (1988). Correlates, causes, effects and treatment of test anxiety. Review of Educational Psychology, 58(1), 47-77.

Jacobi, M. (1991). Mentoring and undergraduate academic success: A literature review. Review of Educational Research, 61(4), 505-532.

Karabenick, S.A. \& Knapp, J.R. (1991). Relationship of academic helpseeking to the use of learning strategies and other instrumental achievement behavior in college students. Journal of Educational Psychology, 83(2), 221-230.

Kulik, C.C., Kulik, J.A., \& Shwalb, B.J. (1983). College programs for high risk and disadvantaged students: A meta-analysis of findings. Review of Educational Research. 53, 397-414.

Lin, Y-G., \& McKeachie, W.J. (1970). Aptitude, anxiety, study habits and academic achievement. Journal of Counseling Psychology, 17(4), 306-309.

McCormick, E.J., Jeanneret, P.R. \& Mecham, R.C. (1989). Position Analysis Questionnaire. West Lafayette, IN: Purdue Research Foundation.

McKeachie, W.J. (1984). Does anxiety disrupt information processing or does poor information processing lead to anxiety? International Review of Applied Psychology, 33, 187-203.

Perry, R.J. \& Penner, K.S. (1990). Enhancing academic achievement in college students through attributional retraining and instruction. Journal of Educational Psychology, 82(2), 262-271. 
Ragins, B.R. \& Cotton, J.L. (1999). Mentor functions and outcomes: A comparison of men and women in formal and informal mentoring relationships. Journal of Applied Psychology, 84(4), 529-550.

Seibert, S. (1999). The effectiveness of facilitated mentoring: A longitudinal quasi-experiment. Journal of Vocational Behaviour, 54, 483-502.

Tremblay, P.F. (1998). Development and construct validation of the academic motivation inventory. Unpublished doctoral dissertation, The University of Western Ontario, London, $\mathrm{ON}$.

Upcraft, M.L. (1989). The freshman year experience: Helping students survive and succeed in college. San Francisco, CA: Jossey-Bass.

\section{Appendix A (Description of motivation measures)}

Stimulation Valence. Students who obtain a high score on this scale are stimulated, excited, and inspired by the academic experience [e.g., "Most of my school projects have been very stimulating experiences" $(+)$, "The lecture material presented in courses is very dry"(-)].

Mastery Valence. Students who obtain a high score on this measure recognize and value the development of new skills and knowledge [e.g., "I want to become a very knowledgeable person"(+), "Learning just for the sake of becoming more educated is a waste of time" $(-)]$.

Recognition Valence. Students who obtain a high score on this measure derive satisfaction from the recognition they receive from peers, teachers, parents, and others [e.g., "I like to impress my teachers" $(+)$, "Recognition in university means very little to me"(-)].

Acquisition Valence. Students who obtain a high score on this scale perceive value in academic work for its possible material rewards and future opportunities [e.g., "I value education because it is the key to my future financial success" $(+)$, "Money motivates me very little to do well in school" $(-)]$.

Self-Efficacy. Students who obtain a high score on this scale are confident about their capability to do well in school [e.g., "I have the ability to be successful in university" $(+)$, "Most of the time I feel insecure about my performance in school"(-)].

Facilitating Anxiety. Students who obtain a high score on this scale are worried and concerned about their studies and progress. However, they are not distressed to the point where their attention is sabotaged. Instead, these students 
work harder in order to minimize their anxiety. Facilitating Anxiety is in a sense, an anxiety induced mobilization of energy, and it is somewhat related to the concept of conscientiousness in that both constructs involve a component of responsibility. No negatively-keyed items were included in the scale because it would be difficult to differentiate negatively-keyed words on this scale from those on a debilitating anxiety scale [e.g., "The fear of failing a test makes me work hard" $(+)$, "A little bit of anxiety really gets me going in my school work" $(+)]$.

Debilitating Anxiety. Students who obtain high scores on this dimension experience fear, worry and uncomfortable arousal during the pursuit of academic studies to the point at which further academic pursuits may be avoided [e.g., "I feel tense most of the time in class" $(+)$, "I get stressed out much less than other students in school"(-)].

Goal Salience. Students who obtain a high score on this scale set challenging and clearly defined personal academic goals for themselves or accept those set by the teacher [e.g., "I like to set goals that make me work hard" $(+)$, "I approach my school work day to day without planning ahead"(-)].

Effort. Students who obtain a high score on this scale expend a large amount of energy in their academic work [e.g., "I work very hard in school" $(+)$, "I try to take courses that demand the least amount of work" $(-)]$.

Attention. Students who obtain a high score on this scale are focused, perceptive and vigilant in class [e.g., "I am attentive to everything the teacher mentions in class" $(+)$, "I often find myself daydreaming in class" $(-)]$.

Persistence. Students who obtain a high score on this scale maintain a high level of effort and attention over an extended period. These students manage to bounce back quickly from distractions and delays [e.g., "I have a lot of endurance when doing school work" $(+)$, "I usually lose interest in a course when I encounter difficulty"(-)]. 